\title{
Tribological behavior of hydrogenated W-C/a-C:H coatings deposited by three different sputtering techniques
}

\author{
F. Lofaj ${ }^{1 *}$, M. Kabátová ${ }^{1}$, M. Klich ${ }^{2}$, D. Medved'l , V. Girman ${ }^{1,3}$ \\ ${ }^{I}$ Institute of Materials Research of the Slovak Academy of Sciences, Watsonova 47, 04001 Košice, Slovakia \\ ${ }^{2}$ Lodz University of Technology, Institute of Materials Science and Engineering, tódz, Poland \\ ${ }^{3}$ Pavol Jozef Šafárik University in Košice, Faculty of Science, Institute of Physics, \\ Department of Condensed Matter Physics, Košice, Slovakia
}

\begin{abstract}
The evolution of structure, mechanical properties and friction behavior of DC magnetron sputtered (DCMS), high power impulse magnetron sputtered (HiPIMS) and high target utilization sputtered (HiTUS) W-C:H coatings was investigated as a function of the addition of acetylene and hydrogen into $\mathrm{Ar}$ atmosphere. The gradual addition of reactive gases caused a transition from PVD toward hybrid PVD-PECVD and even PECVD dominant processes. The coating structure evolved from nanocrystalline toward nanocomposite and amorphous structure with the increase of acetylene addition. Deposition rates in all techniques increased linearly with the increase of acetylene flow until certain saturation limit due to the limited energy available for acetylene fragmentation during hybrid PVD-PECVD deposition. Hardness and coefficient of friction in DCMS and HiTUS W-C:H coatings deposited in this regime followed standard congruent tendencies whereas PECVD dominated deposition process produced coatings with different dependencies. In contrary, HiPIMS W-C:H coatings showed low sensitivity to the influence of acetylene and hydrogen additions. Lower coefficients of friction $(<0.1)$ and moderate hardness (around $20 \mathrm{GPa}$ ) of HiPIMS W-C:H coatings over a wide range of acetylene additions seem to be a principal advantage of HiPIMS compared to DCMS and HiTUS techniques in this class of coatings.
\end{abstract}

Keywords: W-C:H coatings, DC magnetron sputtering (DCMS), high power impulse magnetron sputtering (HiPIMS), high target utilization sputtering (HiTUS), hardness, coefficient of friction.

\section{INTRODUCTION}

Diamond-like carbon (DLC) coatings consist of amorphous carbon with variable ratio of $\mathrm{sp}^{2} / \mathrm{sp}^{3}$ bonds [1]. DLC coatings are often doped with metals, e.g. W, Ti, Ta, Cr, $\mathrm{Mo}, \mathrm{Au}, \mathrm{Ag}$, etc., to reduce residual stresses and to obtain nanocomposite structures with controllable mechanical and tribological properties [2-5]. Such metal carbidecarbon nanocomposites consist of substoichiometric $\mathrm{MeC}_{1-\mathrm{x}}$ nanocrystals embedded in the carbon matrix $[3,5]$. In the case of $\mathrm{Me}=\mathrm{W}, \mathrm{W}-\mathrm{C}$ based coatings spanning from slightly doped DLC up to almost stoichiometric WC coatings can be deposited using a number of techniques. They include plasma enhanced CVD [6-8] or PVD methods based on arc [9] or various magnetron sputtering techniques [5, 10-12]. In the case of dual magnetron sputtering, sputtering from $\mathrm{W}$ (or WC) and C targets is employed and the amount of free carbon phase depends on the ratio between the power applied to each target $[5,10]$. Obviously, this technique produces hydrogenfree $\mathrm{W}-\mathrm{C}$ coatings. In the case of reactive magnetron sputtering, WC target and reactive hydrocarbon (methane, acetylene, ethane, etc.) gas added into the Ar atmosphere

*flofaj@saske.sk

(D) https://orcid.org/0000-0001-8753-554X control the amount of free carbon and hydrogenated W-C:H coatings are produced [10-12]. It should be noted that reactive deposition involving hydrocarbons is different from conventional reactive sputtering. It involves hydrocarbon gas decomposition, strong carbon deposition, and modified hysteresis behavior. Therefore, it is called hybrid PECVDPVD process [13]. The power to the magnetrons may be supplied either in direct current (direct current magnetron sputtering - DCMS) [5, 10], radio frequency sputtering [14] or pulsed (modified pulse power - MPP, or high-power impulse magnetron sputtering - HiPIMS) modes. Recently, a novel sputtering technique called high target utilization sputtering (HiTUS) was also used for the deposition of W-C coatings $[11,12]$.

The presence of hydrogen in DLC is essential for the stabilization of its structure, the presence of residual stresses as well as for final mechanical and tribological properties. The effect of hydrogen originating from added hydrocarbons can be described in terms of saturation of amorphous carbon matrix and closing of the dangling carbon bonds by hydrogen atoms $[15,16]$. High levels of hydrogenation result in residual stress reduction, significant decrease in the coefficient of friction $(\mathrm{CoF})$ and increase the effectiveness of self-lubrication $[17,18]$. The carbon deposition rate is strongly correlated with the flow of hydrogen added into 
the atmosphere: at excessively high flows, the hydrogen ions in the atmosphere can recombine with hydrogen in the amorphous carbon and form gaseous hydrogen molecules $[15,16]$. The incorporation of hydrogen into carbon coating significantly modifies friction behavior [1, 19-22]. Strong dependence of $\mathrm{CoF}$ in dry friction on hydrogen content and humidity was reported for both DLC and W-C:H coatings [18-22]. In humid air, $\mathrm{CoF}$ of around 0.25 was reported for hydrogen-free DLC but less than 0.1 for the hydrogenated coatings. In dry nitrogen atmosphere, $\mathrm{CoF}$ increased up to 0.7 in hydrogen-free DLC but nearly vanishing values (superlubricity regime) were obtained in the hydrogenated coatings $[20,22]$. In ultrahigh vacuum, $\mathrm{CoF} \sim 0.7$ was measured at relatively low hydrogen concentrations but a transition to superlow friction regime happened when the hydrogen concentration was 42 at\% [19]. The reasons for such friction behavior of DLC were attributed to the formation of transfer films with the pivotal role of hydrogen [19-22]. Hydrogen may passivate the dangling $\sigma$-bonds on DLC surface to reduce the adhesive interactions. The presence of oxygen or water had a positive effect on friction in hydrogen-free DLC coatings and detrimental effect on hydrogenated coatings due to the chemical reactions of oxygen or water molecules with dangling carbon bonds [22].

In dual magnetron sputtering deposited nanocomposite hydrogenated W-C:H coatings, the degree of hydrogenations was confirmed to be crucial for low CoFs and values below 0.1 can be obtained at sufficiently high hydrocarbon flows even at relatively high humidity $(20 \%-27 \%)$ [18]. It was also found out that hydrogen incorporation into the carbon matrix caused reduction of the residual stresses and improved adhesion [18, 23]. In our previous studies on W-C:H coatings prepared by hybrid sputtering by DCMS, HiPIMS as well as HiTUS methods, similar CoF values were obtained $[8,11,12,24]$. However, the influence of hydrogen addition during hybrid PVD-PECVD deposition on friction behavior of these coatings was only partially investigated up to now. Therefore, the aim of the current work is to study the effects of hydrogen originating from acetylene and directly added on mechanical properties and tribological behavior of HiPIMS and HiTUS W-C:H coatings in comparison with the reference DCMS coatings.

\section{MATERIALS AND METHODS}

The substrate discs (diameter $25 \mathrm{~mm}$, thickness $3 \mathrm{~mm}$ ) of hardened $100 \mathrm{Cr} 6$ steel and around $2 \mathrm{~cm}^{2}$ fragments of (100) Si wafer were polished and thoroughly ultrasonicated in acetone and ethanol. Then, the substrates were plasma cleaned and up to $\sim 200 \mathrm{~nm}$ Ti bond layer was deposited for DCMS W-C:H coatings whereas Cr bond layer was found to provide better adhesion for HiPIMS and HiTUS W-C:H coatings.

The DCMS and HiPIMS depositions were performed in Cryofox Discovery 500 (Polyteknik, Denmark) PVD system using the same average power $(350 \mathrm{~W})$ applied to stoichiometric $76.2 \mathrm{~mm}$ ( 3 inches) WC target for a constant deposition time of $43 \mathrm{~min}$ and without a bias on the substrates. In the case of HiPIMS, the frequency of 150 $\mathrm{Hz}$ and impulse length of $175 \mu$ s resulted in the duty cycle of $2.62 \%$. Two series of depositions were performed: in the first series, acetylene flows of 0,2, 4 and $6 \mathrm{sccm}$ (and $8 \mathrm{sccm}$ in HiPIMS) were added into Ar atmosphere. In the second series, 10 and $20 \mathrm{sccm}$ of hydrogen flows were added to each (except $2 \mathrm{sccm} \mathrm{C}_{2} \mathrm{H}_{2}$ ) acetylene level. Because of constant gas flow regime during deposition, the added acetylene and/ or hydrogen flows gradually increased the working pressure from the initial $0.5 \mathrm{~Pa}$ (at $25 \mathrm{sccm}$ Ar flow) up to around 0.9 $\mathrm{Pa}$ at the maximum acetylene and hydrogen additions. The HiTUS W-C coatings were deposited in the HiTUS S500 (Plasma Quest, United Kingdom) system using identical targets and with the additions of $0-15 \mathrm{sccm}_{2} \mathrm{H}_{2}$ and $0-15$ sccm $\mathrm{H}_{2}$ into $\mathrm{Ar}$ atmosphere. However, because of the larger vacuum chamber and more powerful turbomolecular pump in HiTUS system, Ar flow had to be increased to $120 \mathrm{sccm}$ to reach the same initial working pressure of $0.5 \mathrm{~Pa}$. Thus, the addition of the reactive gases in the same flow range increased the working pressure much less and the relative gas additions were also much smaller than in DCMS and HiPIMS processes. The constant deposition parameters included the RF power on a remote plasma source of 1500 $\mathrm{W}$ and $500 \mathrm{~W}$ of RF power on the target.

The differences in the plasma composition among the studied deposition techniques and corresponding composition of reactive atmospheres were measured in both deposition systems using external optical emission spectrometer AvaSpec-2048-USB2 (Avantes, The Netherlands) with 2014-pixel CCD linear array detector in transmission/absorbance mode. The light signal was collected by a collimator located around $2 \mathrm{~cm}$ above the target and oriented into the zone with the maximum light intensity. The signal was transferred from the chamber into the spectrometer via optical fiber. The resolution of the spectrometer was $0.6 \mathrm{~nm}$ which reduced possibilities for individual peak separation. Another limitation of the measurements was related to different distances of the collimator from plasma in DCMS/HiPIMS and HiTUS due to different chamber sizes. Therefore, only relative intensities between analogous peaks were compared. The morphology, structure, and thickness of the coatings were observed on the fracture cross sections of coatings on silicon substrates in the scanning electron microscopes (SEM, Auriga Compact, Zeiss, Germany, and JSM 7000F, Jeol, Japan). The details of the W-C:H coating structure were investigated using high resolution transmission electron microscopy (JEM 2100F, Jeol, Japan) on thin foils prepared by a standard procedure involving polishing, dimpling and ion milling.

The nanoindentation tests were performed on a set of 16 indents (matrix $4 \times 4$ indents $25 \mu \mathrm{m}$ apart) with a sharp diamond Berkovich tip (G200, Agilent, USA) in continuous stiffness mode (CSM). The amplitude of the sinusoidal signal was $2 \mathrm{~nm}$ and its frequency was $45 \mathrm{~Hz}$. The strain rate was set to $0.05 \mathrm{~s}^{-1}$ and the load increased until constant indentation depth of $1000 \mathrm{~nm}$ was reached. The zero positions of the 
load-indentation depth curves were manually adjusted and the curves with excessive deviations were excluded from further analysis. The hardness and indentation modulus depth profiles were obtained by averaging of minimum 9 valid indentation measurements. The maximum and/or plateau on the average profiles in the depth range from 100 to around $200 \mathrm{~nm}$ was used as the representative hardness and indentation modulus values of the coatings. This depth range satisfied conditions given by the indenter tip area calibration at small depths and from $10 \%$ depth rule related to coating thickness.

The friction behavior of the studied coatings was investigated at room temperature in a standard tribometer (HTT, CSM Instr./Anton Paar, Switzerland) in the ballon-disc configuration with static 100Cr6 ball (diameter 6 $\mathrm{mm}$ ) without any lubricant. The tests were performed on the coatings deposited on steel substrates rotating in one direction with the sliding speed of around $10 \mathrm{~cm} / \mathrm{s}$ at room temperature in air with the humidity kept at $30 \% \pm 2 \%$. Normal load of $1 \mathrm{~N}$ used in the tests on DCMS and HiPIMS coatings was selected in such a way that the mean Hertzian contact stress was around $930 \mathrm{MPa}$ and the maximum von Mises stress of around $580 \mathrm{MPa}$ underneath the contact zone was below the yield stress of the substrate. The load of $10 \mathrm{~N}$ was used for the tests on HiTUS coatings. The corresponding wear tracks were observed by optical microscopy (Axio Observer, Zeiss, Germany).

\section{RESULTS AND DISCUSSION}

\section{Hybrid sputtering in DCMS, HiPIMS and HiTUS plasma}

The W-C:H coating growth occurs due to condensation of the particle flux toward the substrate. The flux consists of species sputtered from the target and from the hydrocarbon fragments, various ions and atomic hydrogen obtained by dissociation and ionization of acetylene and hydrogen in $\mathrm{Ar}$ atmosphere [25-30]. Fig. 1a compares the spectra obtained during sputtering of WC without the addition of acetylene into the Ar atmosphere. Because the spectra were composed mostly of numerous Ar peaks which could not be separated due to the relatively low resolution of the spectrometer, only selected well-defined peaks were indicated and used for comparison. Moreover, because the conditions for spectra accumulation in different sputtering techniques varied in different PVD systems, only relative intensities between neighboring peaks should be considered. Besides absolutely dominant peaks of argon ion in all spectra, the presence of $\mathrm{W}$ neutrals and a small peak of $\mathrm{C}^{1+}$ were detected. The differences among spectra in DCMS, HiPIMS and HiTUS modes are related only to the absolute intensities. The addition of acetylene caused an increase of the intensity of $\mathrm{C}^{1+}$ ions peak at $515 \mathrm{~nm}$ in HiPIMS and generally higher intensities of $\mathrm{Ar}$ in HiPIMS and HiTUS modes compared to DC mode (Fig. 1b). Other changes could not be visualized with the current resolution of the spectrometer.

The addition of acetylene and subsequent hybrid
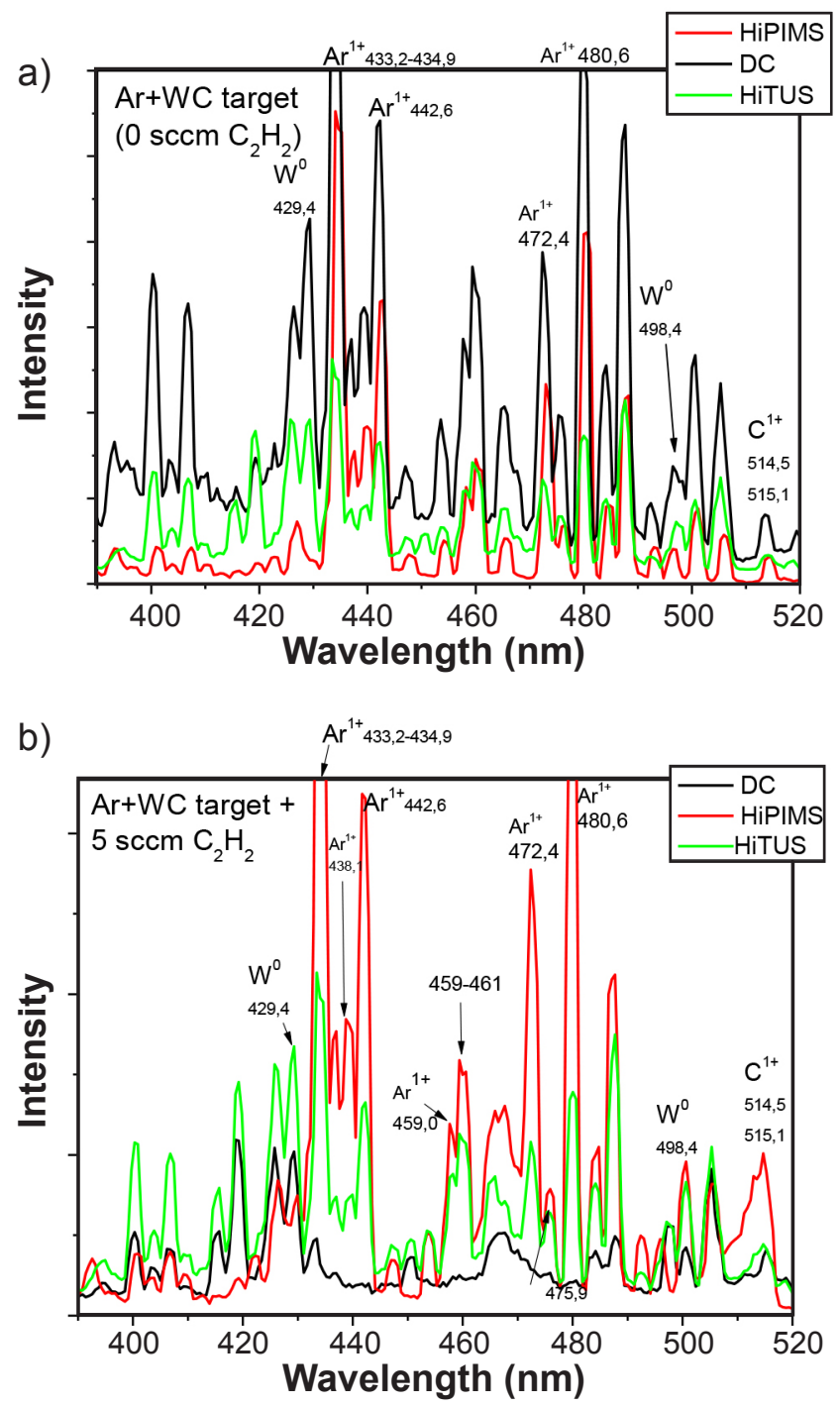

Figure 1: Comparison of the optical emission spectra of plasma during DC magnetron sputtering, HiPIMS and HiTUS when: a) WC target was sputtered in pure Ar atmosphere; and b) in the Ar atmosphere with $5 \mathrm{sccm}$ acetylene flow. The absolute intensities were affected by different measurement conditions and only the relative changes between peaks should be considered.

PECVD-PVD processes resulted in a special type of WC target poisoning. Compared to clean target in the case of sputtering in pure Ar, acetylene addition caused the formation of three zones outside and inside of the clean racetrack with variable $\mathrm{C} / \mathrm{W}$ ratio (Fig. 2a). Rough estimates by energy dispersive X-ray spectroscopy (EDS) showed that the $\mathrm{C} / \mathrm{W}$ ratio in the racetrack was close to 1 indicating pure WC. The ratio increased above unity in the first darker zones surrounding racetrack in both radial directions. It was followed by the black zones with gradually increasing carbon concentration. The subsequent zone center contained a large excess of carbon $(\mathrm{C} / \mathrm{W}>>1)$ and even soot-like deposits were seen in the center and at the outer rim of the target. No significant differences were noticed between the DCMS and HiPIMS modes. Although EDS did not provide a possibility to distinguish between carbon in the WC 
phase and free carbon, Fig. 2a clearly indicated substantial differences from conventional target poisoning. Carbon deposits similar to poisoning prevailed only in specific zones whereas racetrack itself remained clean. Racetrack poisoning did not occur because no metallic tungsten was present which could chemically interact with carbon to form new carbide phases (or this phase could not be distinguished from the existing WC target). Thus, the principal differences of the hybrid PVD-PECVD sputtering compared to standard reactive sputtering included: no racetrack poisoning, hysteresis effects observed in standard reactive processes were substantially suppressed and target 'poisoning' in this case meant only carbon deposits in low sputtering rate zones. Fig. $2 b$ shows that in HiTUS, not only racetrack but even the carbon deposits were absent. The absence of racetrack is an inherent characteristic of this technique responsible for its name and results from a separation of plasma source and target. Broad Ar ion beam then caused relatively homogeneous sputtering from the whole target and carbon deposits could not form in a similar way as in the racetrack zone in magnetron sputtering. The absence of carbon deposits agrees with already reported absence of hysteresis behavior [11]. The addition of hydrogen did not change the overall picture observed in all three technologies.

\section{Coating preparation and deposition rates}

The sets of W-C:H coatings deposited by HiPIMS and HiTUS techniques were compared with the reference coatings prepared by conventional DC magnetron sputtering. The deposition conditions, coating thicknesses, and corresponding deposition rates are summarized in Table I. The thicknesses of the coatings were in the range from $0.5 \mu \mathrm{m}$ up to around $3 \mu \mathrm{m}$ depending on the deposition conditions, especially on acetylene/Ar flow ratio and deposition time. The deposition rates in DCMS and HiPIMS can be compared directly because of the same target-substrate distance, $d=7$ $\mathrm{cm}$. However, because target-substrate distance $\mathrm{d}=17 \mathrm{~cm}$ in HiTUS chamber, the absolute values of the deposition rates are not directly comparable with those in DCMS/HiPIMS cases.

The deposition rates as a function of relative $\mathrm{C}_{2} \mathrm{H}_{2} / \mathrm{Ar}$ ratio in DCMS, HiPIMS and HiTUS are compared in Fig. 3. The rates in DCMS and HiPIMS can be described by linear dependencies with different slopes. Up to a certain limit, rates linearly increased with the increase of relative acetylene additions. When the limit was exceeded, the slope of the dependence changed to zero and saturation occurred. The differences between DCMS and HiPIMS processes were in the absolute deposition rates and in the saturation limits. The saturation limit in DCMS was reached at $4 \mathrm{sccm}$ $\mathrm{C}_{2} \mathrm{H}_{2}$ whereas it was $6 \mathrm{sccm} \mathrm{C}_{2} \mathrm{H}_{2}$ in HiPIMS. The deposition rates below these limits in DCMS were 3-5 times higher than in HiPIMS W-C:H coatings. However, the saturation rates of around $1.4 \mathrm{~nm} / \mathrm{s}$ were identical. The behavior in HiTUS coatings exhibited some differences besides lower values due to larger target-substrate distance. The deposition rates followed one linear dependence up to $\mathrm{C}_{2} \mathrm{H}_{2} / \mathrm{Ar}=0.067$ (8 sccm of $\mathrm{C}_{2} \mathrm{H}_{2}$ ) and at higher $\mathrm{C}_{2} \mathrm{H}_{2} /$ Ar ratios, another linear dependence with the slope much higher than in DCMS and HiPIMS processes. Moreover, no saturation was observed within the studied acetylene addition range.

The above dependencies of deposition rate in the hybrid PVD-PECVD magnetron sputtering can be qualitatively understood based on the energy balance between PVD and PECVD processes. The addition of acetylene into the atmosphere resulted in a gradual increase of the contribution of PECVD processes relative to the PVD process represented by conventional magnetron sputtering of WC target. In the first approximation, PVD and PECVD can be considered as independent and additive. This assumption should be valid when PVD contribution is larger than that of PECVD, i.e. at relatively low acetylene additions. The constant power of 350 $\mathrm{W}$ applied to the magnetron in the PVD process was partially consumed for the ionization of $\mathrm{Ar}$ and sputtering from the target. When acetylene is added, its decomposition involved in PECVD processes would consume additional energy from an unused part of total energy. The linear increase of growth rate above the deposition rate of pure WC coating would be attributed to the deposition of the fragments from acetylene. Because of constant total power, the linear rate increase may occur only until the flow of acetylene reaches a level when the energy remaining after WC sputtering is consumed. Therefore, an acetylene flow limit resulting in a transition to saturation appears. At the flows above that saturation limit, deposition rate stays constant (Fig. 3) and the excess acetylene would be just pumped away. Fig. 3 also indicates that the behavior in DCMS and HiPIMS was principally the same, the differences were only in the absolute values of deposition rate and saturation limits. Lower deposition rates are typical for HiPIMS and slightly higher saturation limit in HiPIMS may be related to higher effectivity of short high energy density pulses in decomposition analogous to higher ionization level at the same average power [31].

Because the processes of WC sputtering and acetylene decomposition in HiTUS have to be principally the same as in magnetron sputtering, the same energy balance considerations should be applied. The simplest idea to explain the observed differences is that the data at very small acetylene additions (below $\mathrm{C}_{2} \mathrm{H}_{2} / \mathrm{Ar}=0.067$ which
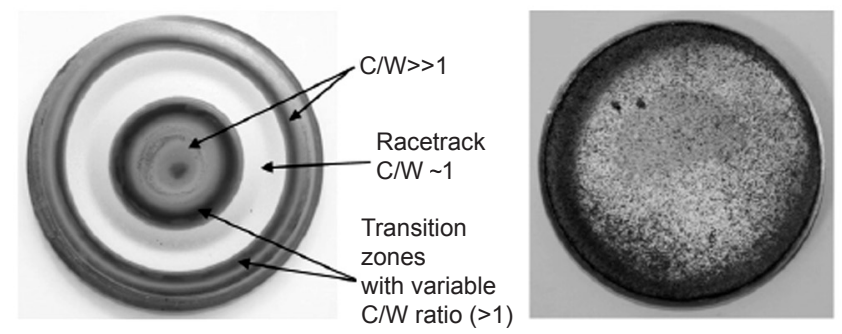

Figure 2: 'Poisoning' of WC targets after hybrid PVD-PECVD processes: a) in the $\mathrm{Ar}$ atmosphere with the addition of $6 \mathrm{sccm}$ $\mathrm{C}_{2} \mathrm{H}_{2}+20 \mathrm{sccm} \mathrm{H}_{2}$ in DCMS and HiPIMS; and b) in the analogous atmosphere in HiTUS. 
Table I - Deposition conditions of the studied DCMS, HiPIMS, and HiTUS W-C:H coatings.

\begin{tabular}{|c|c|c|c|c|}
\hline Conditions & $\mathrm{C}_{2} \mathrm{H}_{2}$ flow $(\mathrm{sccm})$ & $\mathrm{H}_{2}$ flow $(\mathrm{sccm})$ & Thickness $^{+}(\mathrm{nm})$ & Deposition rate* $(\mathrm{nm} / \mathrm{s})$ \\
\hline \multicolumn{5}{|c|}{ DCMS } \\
\hline \multirow{10}{*}{$\begin{array}{c}\text { DC power } \mathrm{P}=350 \mathrm{~W} \\
\text { Deposition time } \mathrm{t}=43 \mathrm{~min} \\
\text { Working pressure } \mathrm{p}_{\mathrm{Ar}} \geq 0.5 \\
\mathrm{~Pa}^{\#}(25 \mathrm{sccm} \mathrm{Ar}) \\
\text { Substrates: } 100 \mathrm{Cr} 6, \mathrm{Si} \\
\text { Ti bond layer }\end{array}$} & & 0 & $1900-2470$ & $0.74-0.96$ \\
\hline & 0 & 10 & $1650-2056$ & $0.64-0.80$ \\
\hline & & 20 & $1336-1528$ & $0.52-0.59$ \\
\hline & 2 & 0 & $2725-3040$ & $1.06-1.18$ \\
\hline & \multirow{3}{*}{4} & 0 & $3030-3575$ & $1.17-1.39$ \\
\hline & & 10 & $1280-2890$ & $0.50-1.12$ \\
\hline & & 20 & $1014-2510$ & $0.39-0.97$ \\
\hline & \multirow{3}{*}{6} & 0 & $3130-3600$ & $1.21-1.39$ \\
\hline & & 10 & $2481-3710$ & $0.96-1.44$ \\
\hline & & 20 & $2500-2544$ & $0.97-0.99$ \\
\hline \multicolumn{5}{|c|}{ HiPIMS } \\
\hline \multirow{11}{*}{$\begin{array}{c}\text { Average power } \mathrm{P}_{\mathrm{av}}=350 \mathrm{~W} \\
\text { Frequency } \mathrm{f}=150 \mathrm{~Hz} \\
\text { Impulse length } \mathrm{t}=175 \mu \mathrm{s} \\
\text { Deposition time } \mathrm{t}=43 \mathrm{~min} \\
\text { Working pressure } \mathrm{p}_{\mathrm{Ar}} \geq 0.5 \\
\mathrm{~Pa}^{\#}(25 \mathrm{sccm} \mathrm{Ar}) \\
\text { Substrates: } 100 \mathrm{Cr} 6, \mathrm{Si} \\
\text { Ti or Cr bond layer }\end{array}$} & \multirow{3}{*}{0} & \multirow{3}{*}{0} & $514-879$ & $0.20-0.34$ \\
\hline & & & 525 & 0.20 \\
\hline & & & 496 & 0.19 \\
\hline & 2 & \multirow{4}{*}{$\begin{array}{c}0 \\
0 \\
10 \\
20\end{array}$} & $1045-1890$ & $0.40-0.73$ \\
\hline & \multirow{3}{*}{4} & & $2600-2900$ & $1.01-1.12$ \\
\hline & & & 3100 & 1.20 \\
\hline & & & $2660-2733$ & $1.03-1.06$ \\
\hline & \multirow{3}{*}{6} & 0 & $3340-3620$ & $1.29-1.40$ \\
\hline & & 10 & 2575 & 1.0 \\
\hline & & 20 & $3238-3427$ & $1.25-1.33$ \\
\hline & 8 & 0 & 3553 & 1.38 \\
\hline \multicolumn{5}{|c|}{ HiTUS } \\
\hline \multirow{5}{*}{$\begin{array}{l}\text { Plasma source RF power } \\
\mathrm{P}_{\mathrm{RF}}=1500 \mathrm{~W} \\
\text { Target } \mathrm{RF} \text { power } \mathrm{P}_{\mathrm{wC}}=500 \\
\mathrm{~W}\end{array}$} & 0 & \multirow{6}{*}{0} & $550(20 \mathrm{~min})$ & 0.46 \\
\hline & 1 & & $500(20 \mathrm{~min})$ & 0.42 \\
\hline & 5 & & $600(20 \mathrm{~min})$ & 0.50 \\
\hline & 8 & & $650(20 \mathrm{~min})$ & 0.54 \\
\hline & 12 & & $1200(20 \mathrm{~min})$ & 1.00 \\
\hline Deposition time: $\mathrm{t}=20$ or & 15 & & $1500(20 \mathrm{~min})$ & 1.25 \\
\hline $\begin{array}{l}60 \text { min } \\
\text { Working pressure } \mathrm{p} \geq 0.5\end{array}$ & \multirow{5}{*}{8} & 0 & $930-1120(60 \mathrm{~min})$ & $0.26-0.31$ \\
\hline $\begin{array}{l}\text { Woring pressure } \mathrm{p}_{\mathrm{Ar}} \geq 0.5 \\
\mathrm{~Pa}^{\#}(120 \mathrm{sccm} \mathrm{Ar})\end{array}$ & & 4 & $930-1230(60 \mathrm{~min})$ & $0.26-0.34$ \\
\hline Substrates: 100Cr6, Si & & 8 & $1030-1390(60 \mathrm{~min})$ & $0.29-0.39$ \\
\hline Cr bond layer & & 10 & $720-1250(60 \mathrm{~min})$ & $0.20-0.35$ \\
\hline & & 15 & $840-1050(60 \mathrm{~min})$ & $0.23-0.29$ \\
\hline
\end{tabular}

${ }^{+}$- thickness range reflected thickness variations on different substrates and from multiple measurements; * - target-substrate distance was $17 \mathrm{~cm}$ in HiTUS whereas it was only $7 \mathrm{~cm}$ in the case of DCMS and HiPIMS; ; $-p_{A r}=0.5$ Pa corresponded to the working pressure of pure Ar atmosphere; the pressure increased with the addition of acetylene and hydrogen .

were not investigated in DCMS and HiPIMS experiments) corresponded to PVD process of WC sputtering rather than to hybrid PVD-PECVD processes. Then, the hybrid processes in HiTUS and magnetron sputtering techniques can be fairly compared only at $\mathrm{C}_{2} \mathrm{H}_{2} / \mathrm{Ar} \geq 0.067$. The considerably higher slope of linear dependence in HiTUS in that acetylene flow range seems to be a consequence of substantially higher RF power $(1500 \mathrm{~W})$ to generate HiTUS plasma and the RF power $(500 \mathrm{~W})$ applied to the target. Similarly, as in HiPIMS, a higher power may result in better utilization of the precursor gas and higher deposition rates. It would also be a reason why no saturation limit was observed: it is shifted to higher acetylene flows which were not investigated in the current study. Surprisingly, the spectra in Fig. 1b provide no direct evidence for such explanation. Additional experiments with higher acetylene additions to reach saturation and optical emission spectroscopy measurements of plasma composition with better resolution are required to support the above ideas.

The data in Table I also indicate that the addition of $\mathrm{H}_{2}$ caused a noticeable decrease in the deposition rates in DCMS whereas only a small decrease in deposition rates was observed in HiPIMS and HiTUS coatings. The understanding of these hydrogen effects should be based on the growth 


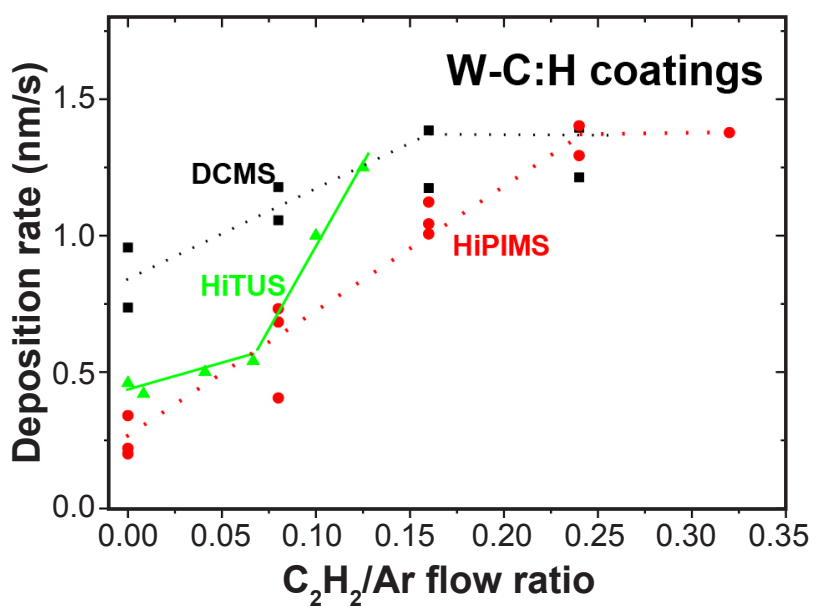

Figure 3: Comparison of the deposition rates in dependence on the $\mathrm{C}_{2} \mathrm{H}_{2} / \mathrm{Ar}$ flow ratio in the studied DCMS, HiPIMS, and HiTUS $\mathrm{W}-\mathrm{C}: \mathrm{H}$ coatings.

models of a-C:H and W-C:H coatings from hydrocarbon precursors $[15,16,25-30]$. These growth models assume that the growth rate, which increases above the rate resulting from solid target (carbon or WC, respectively) sputtering, is given by mostly $\mathrm{C}_{2} \mathrm{H}_{\mathrm{x}}{ }^{+}$ions $(\mathrm{x}=0,1,2, \ldots)[15,16,27-29]$ coming from the acetylene fragmentation and subsequent reactions among them. The most important ion-related processes for coating growth involve direct incorporation of carbon-containing ions and dehydrogenation by preferential displacement of bonded $\mathrm{H}$ atoms. The above hydrocarbon fragments adsorb at the growing surface but their chemical bonding for incorporation into the coating structure may happen only at active sites also called 'dangling bonds'. Such dangling bonds may be created by hydrogen extraction from the hydrocarbon at or just below the surface [27-30]. The hydrogen displacement occurs much easier than the break of $\mathrm{C}-\mathrm{C}$ bonds because only $3 \mathrm{eV}$ are required compared to 25 $\mathrm{eV}$ for $\mathrm{C}-\mathrm{C}$ bonds [32]. Displaced atomic hydrogen locally recombines to form volatile molecular hydrogen. Such a mechanism enables continuous generation of activation sites where hydrocarbon radicals can continuously attach and coating can grow [30]. Another mechanism is that the $\mathrm{C}_{2} \mathrm{H}_{x}$ radicals change the hybridization from $\mathrm{sp}^{1}$ to $\mathrm{sp}^{2}$ or $\mathrm{sp}^{3}$ upon adsorption [27, 28]. Both mechanisms strongly depend on the hydrogen concentration in the plasma and on the energy of the impinging ions. At low energies corresponding to a floating potential, relatively low concentration of dangling bonds at the surface is further decreased by the increase of hydrogen concentration. At higher energies, the resulting rate is controlled by the balance between the rate of creation of new dangling bonds by ion bombardment and attachment of the impinging species [26-29]. Thus, a reduction of the deposition rates can be expected which qualitatively agrees with the current observations.

\section{Coating structure and composition}

High-resolution transmission electron microscopy micrographs in Fig. 4 provide a comparison of the structures of W-C:H coatings deposited using different techniques and with different additions of acetylene and hydrogen. Pure DCMS WC coating (Fig. 4a) consisted of crystallites with the diameter in the range of $\sim 20 \mathrm{~nm}$ elongated perpendicularly toward the substrate. It agrees with our earlier X-ray diffraction studies which reported textured structure in this coating [24]. At small additions of acetylene (Fig. 4b), texture disappeared and a nanocomposite structure consisting of the crystallites with the diameter of about 10 $\mathrm{nm}$ in an amorphous matrix was formed. Such crystallites were usually attributed to $\mathrm{WC}_{1-\mathrm{x}}$ phase and the matrix to amorphous carbon $[5,10,18]$ which agrees with our earlier studies [11, 12, 24]. Higher additions of acetylene (Fig. 4c) produced fully amorphous coatings regardless of the hydrogen addition. Thus, single PVD process produced textured $\mathrm{WC}_{1-\mathrm{x}}$ coating whereas hybrid sputtering with the increasing amount of acetylene resulted in a gradual transition from nanocomposite to amorphous W-C:H coatings. In HiPIMS, textured WC structure from DCMS was replaced by randomly oriented nanocrystalline structure (Fig. 4d); further evolution in hybrid sputtering followed the same path as in DCMS. HiTUS produced very similar structures as in HiPIMS: pure Ar atmosphere produced a structure consisting of nanocrystals with the size of around $5 \mathrm{~nm}$ (Fig. 4e). The addition of small amount of acetylene caused that an amorphous (hydrogenated) carbon binding phase appeared among the nanocrystals while their size remained approximately the same (Fig. 4f). At even higher acetylene additions, a fully amorphous structure was formed (Fig. $4 \mathrm{~g}$ ). The evolution of the coating structure with the increase of the amount of amorphous carbon phase via acetylene addition at the expense of crystalline WC phase complies with the earlier discussed hydrocarbon radical's contribution to the growth rate in hybrid PVD-PECVD deposition. In agreement with Fig. 4, nucleation and growth of WC clusters and nanocrystals on the growing surface were gradually suppressed when carbon matrix content increased. Regardless of the deposition technique, the fully amorphous structure formed when WC molecules were 'dissolved' in the amorphous matrix.

Despite strong influence of hydrogenation (and hybridization) on the structure and properties of W-C:H coatings reported in the literature [18, 28], Fig. 4 did not show a visible influence of hydrogen on the structure at the atomic level. Coating structure and properties are usually related to the average hydrogen concentrations obtained at macroscale with the elastic recoil data analysis (ERDA)/ Rutherford backscattering (RBS), forward recoil elastic scattering (FRES) [19] or secondary ion mass spectroscopy (SIMS) measurements [18]. Our recent ERDA/RBS measurements on the above DCMS W-C:H coatings [24] indicated that maximum $\sim 35$ at $\%$ of hydrogen can be incorporated into the carbon matrix under studied conditions and acetylene/hydrogen addition range, and acetylene is more effective in hydrogenation than molecular hydrogen. This is in full agreement with the earlier studies $[6,7,18]$. However, additional ERDA measurements are required to 

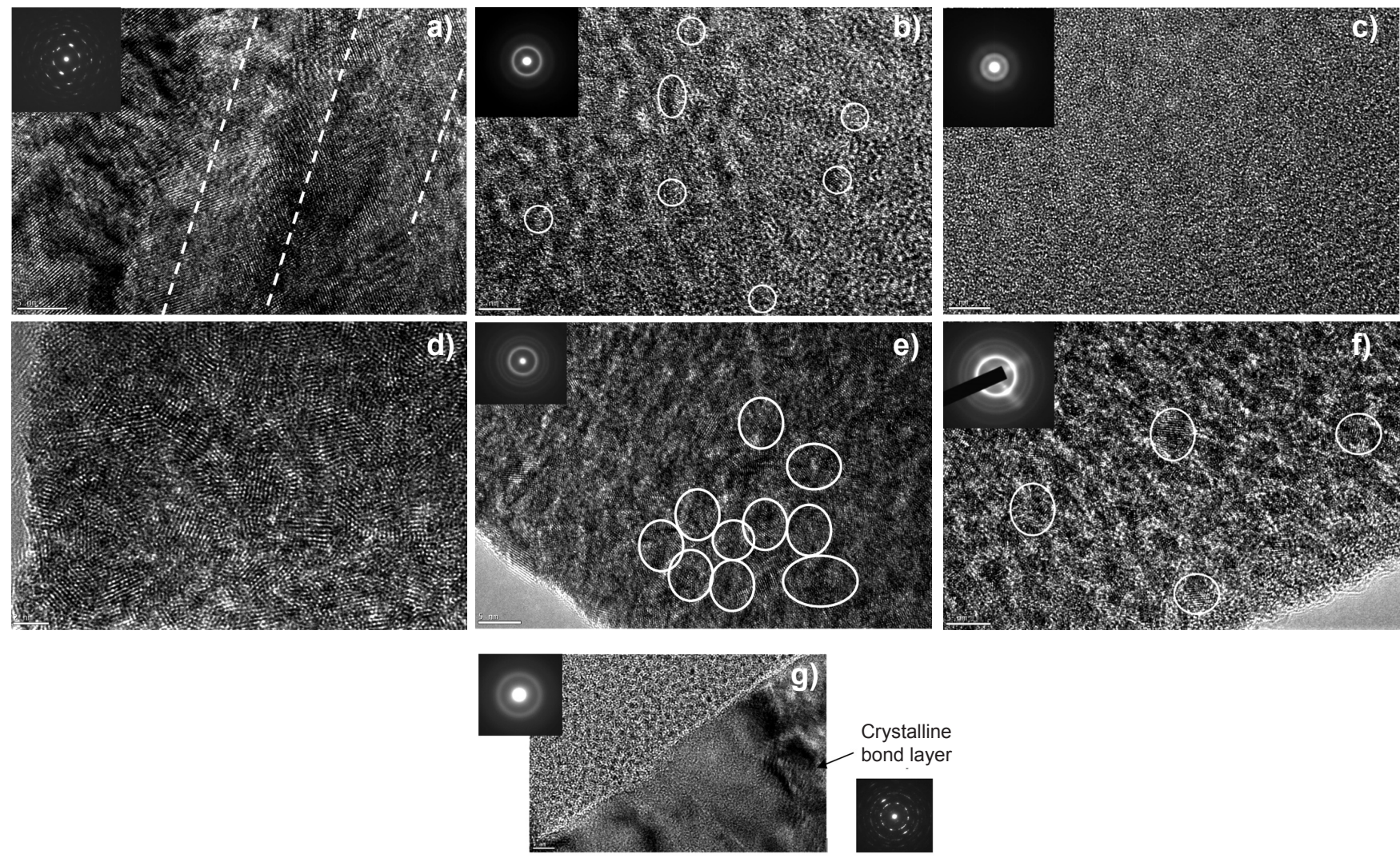

Figure 4: Micrographs obtained by high resolution transmission electron microscopy (HRTEM) showing the structure of the DCMS, HiPIMS and HiTUS W-C:H coatings deposited with different amount of acetylene in Ar atmosphere: a) DCMS - $0 \mathrm{sccm}_{2} \mathrm{C}_{2}$; b) DCMS

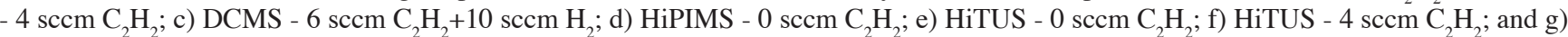
HiTUS - $12 \mathrm{sccm} \mathrm{C}_{2} \mathrm{H}_{2}$. A transition from nanocrystalline to nanocomposite and then to amorphous structure with the increase of acetylene flow is implied. Magnification bar $=5 \mathrm{~nm}$, except in $(\mathrm{d})=2 \mathrm{~nm}$ and $(\mathrm{g})=3 \mathrm{~nm}$.

draw correlations among acetylene and hydrogen additions and hydrogenation level in the current HiPIMS and HiTUS W-C:H coatings compared to DCMS coatings.

\section{Mechanical properties vs. acetylene and hydrogen additions}

Hardness and indentation modulus of W-C:H coatings on steel and $\mathrm{Si}$ substrates were determined from the maxima of the corresponding hardness- and indentation modulus-indentation depth profiles generated by CSM measurements. The obtained values data for DCMS and HiPIMS coatings are summarized in Fig. 5 and in Fig. 6 for HiTUS coatings. Because the differences between the measured properties on steel and $\mathrm{Si}$ substrates were small and not systematic, the data in Fig. 5 were grouped into shaded areas to make the tendencies more visible. The comparison of hardness and indentation modulus behavior in DCMS and HiPIMS W-C:H coatings implies remarkable differences, especially at higher acetylene flows. The hardness of the textured nanocrystalline WC coating (Fig. 5a) was around $37 \mathrm{GPa}$ which is just below the hardness of basal planes of WC microcrystals (43-40 $\mathrm{GPa}$ ) [33]. Lower values in the coatings may be attributed to the deviations of the textured nanocrystals from the ideal orientation and to the presence of boundaries among them. Addition of acetylene in DCMS resulted in nanocomposite structure (Fig. 4b) and in a fast drop of hardness $\mathrm{H}_{\mathrm{IT}}$ (Fig. 5a) and indentation modulus $\mathrm{E}_{\mathrm{IT}}$ (Fig. 5b) to around 20-25 and 250-190 GPa, respectively. This hardness is just below the hardness of prismatic planes of WC crystals (28 GPa) [33] and can be related to the presence of grain boundaries and a softer carbon matrix. The properties of coating remained approximately constant in the range of acetylene additions from 2 to $4 \mathrm{sccm}$, when nanocomposite structure can be expected. At $6 \mathrm{sccm} \mathrm{C}_{2} \mathrm{H}_{2}$ addition when the fully amorphous structure was produced (Fig. 4c), $\mathrm{H}_{\mathrm{IT}}$ and $\mathrm{E}_{\mathrm{IT}}$ of DCMS degraded below 5 and $50 \mathrm{GPa}$, respectively, which are values typical for soft polymeric carbon coatings. The additions of hydrogen caused no or only negligible decrease of the corresponding hardness (Fig. 5c).

The properties of HiPIMS coatings were subjected to considerably smaller changes. Randomly oriented nanocrystalline WC coating (Fig. 4d) exhibited slightly lower $\mathrm{H}_{\text {IT }}(28-30 \mathrm{GPa})$ and $\mathrm{E}_{\text {IT }}(290-330 \mathrm{GPa})$ than in DCMS coatings. Because of the polycrystalline structure, the obtained values were lower than in the textured structure but higher than in nanocomposite structure due to the absence of softer carbon phase. The addition of $2 \mathrm{sccm}$ of acetylene resulted in the same values as in DCMS, most 

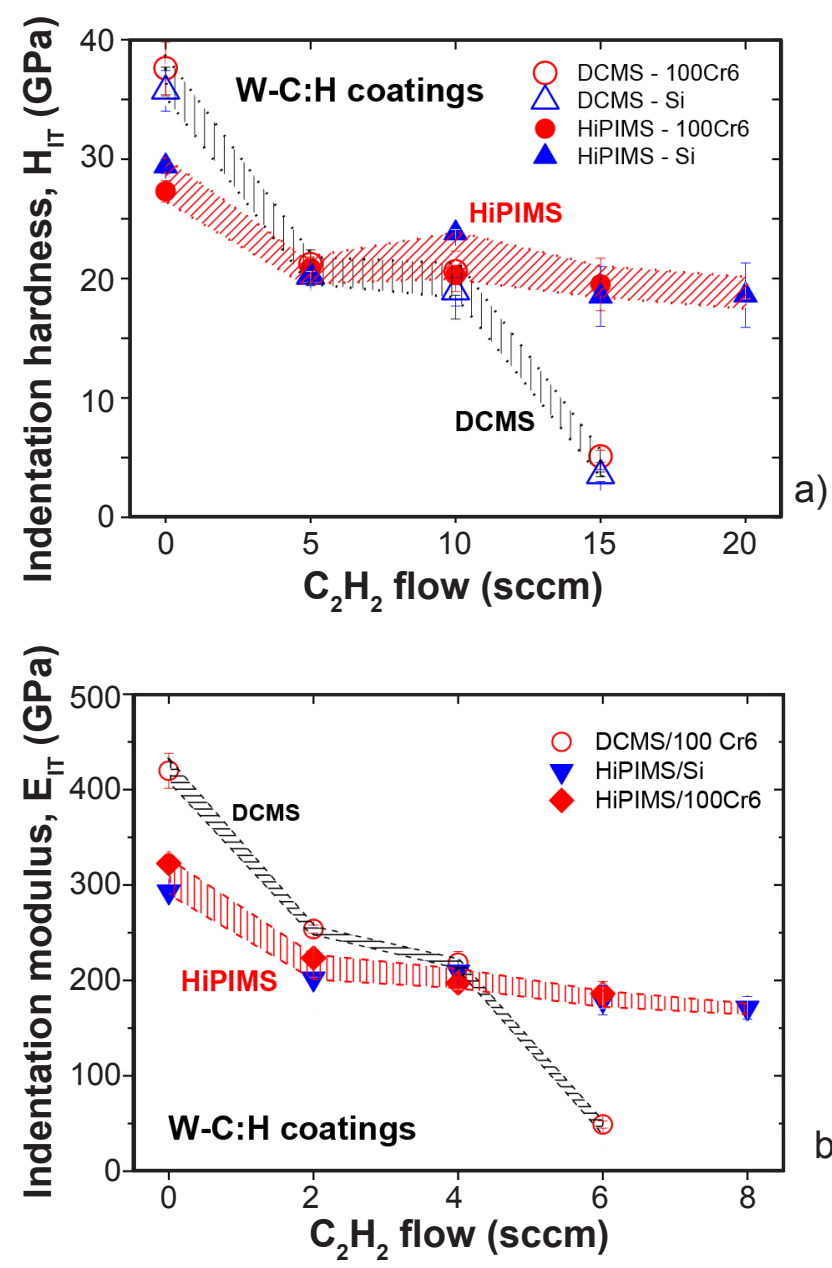

b)

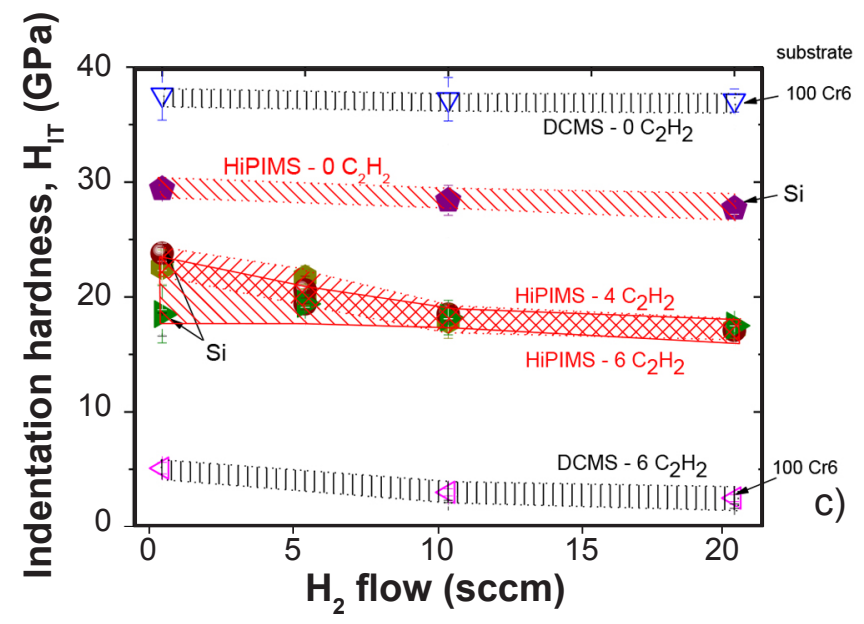

Figure 5: Dependencies of indentation hardness, $\mathrm{H}_{\mathrm{IT}}$ (a), and indentation modulus, $\mathrm{E}_{\mathrm{IT}}$ (b), in the studied DCMS (open symbols) and HiPIMS (closed symbols) W-C:H coatings on 100Cr6 steel and $\mathrm{Si}$ wafer substrates as a function of acetylene flow; in (c), the effect of hydrogen addition on hardness at different acetylene additions is shown.

probably because of the similar nanocomposite structure. At acetylene additions above $4 \mathrm{sccm}$ and up to $8 \mathrm{sccm}$, no or only very small degradation of $\mathrm{H}_{\mathrm{IT}}$ and $\mathrm{E}_{\mathrm{IT}}$ values were observed. Subsequently, the most significant differences in properties between DCMS and HiPIMS coatings appeared
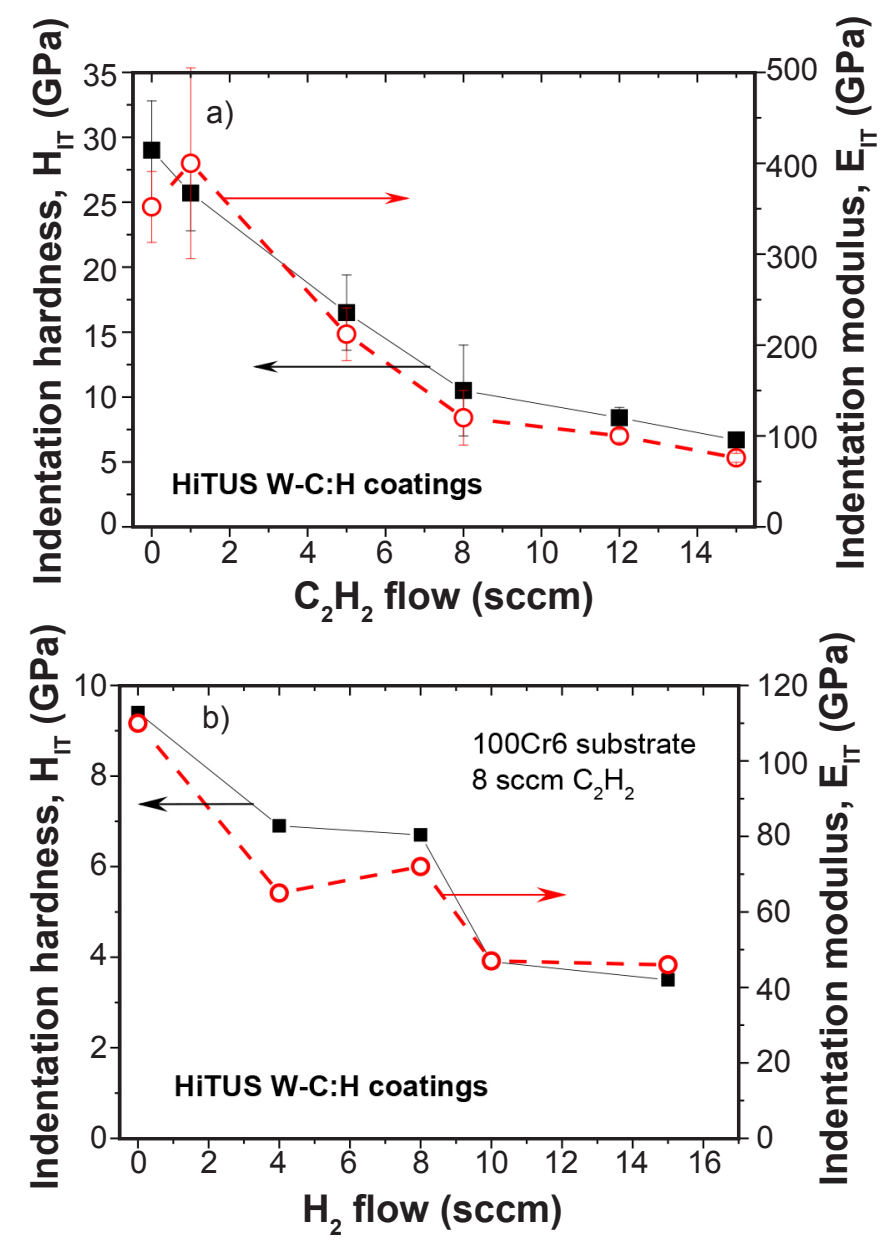

Figure 6: Hardness and indentation modulus dependencies in HiTUS W-C:H coatings on steel substrates on: a) acetylene flow; and b) hydrogen flow at $8 \mathrm{sccm}$ acetylene addition.

at $6 \mathrm{sccm}$ acetylene addition. The reason why HiPIMS coatings were able to keep their properties over a much wider range of acetylene additions seems to be related to better properties of carbon matrix in nanocomposite $\mathrm{W}-\mathrm{C}: \mathrm{H}$ coatings produced by HiPIMS. In the case of HiTUS coatings (Fig. 6), the measured hardness and indentation modulus values were in the same range as in the DCMS coatings despite the relative acetylene additions, defined as flow $\mathrm{C}_{2} \mathrm{H}_{2} /\left(\right.$ flow $\mathrm{Ar}$ fllow $\left.\mathrm{C}_{2} \mathrm{H}_{2}\right)$, in HiTUS were much lower $\left(0.06\right.$ vs. 0.19 at $\left.8 \mathrm{sccm}_{2} \mathrm{C}_{2}\right)$ than in DCMS case. The main difference in acetylene flow dependencies (Fig. 6a), besides slightly lower absolute values, was that $\mathrm{H}_{\text {IT }}$ and $\mathrm{E}_{\mathrm{IT}}$ degradation occurred continuously, without a range of 'stability' observed in DCMS and HiPIMS coatings. The addition of hydrogen (Fig. 6b) caused small degradation in absolute values $\left(<5 \mathrm{GPa}\right.$ in $\left.\mathrm{H}_{\mathrm{IT}}\right)$ but it corresponded to substantial relative changes because of low initial hardness.

\section{Friction behavior}

Fig. 7 demonstrates the effects of acetylene and hydrogen additions on time evolution of the coefficients of friction in DCMS and HiPIMS W-C:H coatings. The main differences were related to the so-called run-in period which corresponds 
to a time and/or distance required for the elimination of significant spikes and stabilization of CoF value. In DCMS coatings without and with small (2 and $4 \mathrm{sccm})$ acetylene additions, friction curves exhibited relatively short (from 5 to $15 \mathrm{~min}$ ) run-in periods followed by a stable stage with $\mathrm{CoF} \sim 0.3$ (Fig. 7a). At $6 \mathrm{sccm} \mathrm{C}_{2} \mathrm{H}_{2}$ flow, around $3 \mathrm{~h}$ was required for $\mathrm{CoF}$ to stabilize at the same value. In DCMS W-C:H coatings with $4 \mathrm{sccm}$ acetylene, the addition of 20 sccm hydrogen increased the length of the run-in period to $\sim 15 \mathrm{~h}$ (Fig. $7 \mathrm{~b}$ ) but CoF was reduced to considerably lower value 0.07 . This points out to the role of hydrogen in $\mathrm{CoF}$ reduction. In HiPIMS coatings (Fig. 7c), lower CoF values $(\sim 0.1)$ were obtained at slightly lower acetylene additions and within shorter run-in periods: only $10 \mathrm{~min}$ at $2 \mathrm{sccm}$ acetylene addition. At $4 \mathrm{sccm} \mathrm{C}_{2} \mathrm{H}_{2}$, run-in period of almost $4 \mathrm{~h}$ was approximately the same as in DCMS coatings with 6 sccm $\mathrm{C}_{2} \mathrm{H}_{2}$ addition. At $6 \mathrm{sccm} \mathrm{C}_{2} \mathrm{H}_{2}$, run-in period span for around $6 \mathrm{~h}$ and $\mathrm{CoF} \sim 0.15$ was stable during extremely long time (Fig. 7d). The wear track after almost $17 \mathrm{~h}$ of testing (sliding distance of around $6.3 \mathrm{~km}$ ) in Fig. 8a shows only few continuous scratches, which may be produced during run-in period [34] without any measurable worn volume. An addition of $20 \mathrm{sccm}$ hydrogen only slightly shortened run-in period, reduced $\mathrm{CoF}$ to around 0.07 and wear track exhibited also no wear (Fig. 8b) similarly as in DCMS deposited with large additions of acetylene and hydrogen. Despite lack of direct evidence (no difference in the Raman spectra from the pristine coating and in the wear track was observed), long run-in period, low $\mathrm{CoF}$ and wear suppression in DCMS and HiPIMS W-C:H coatings with higher amount of hydrogenated carbon point toward the formation of a continuous lubricious tribolayer similar to the tribolayers indicated in undoped a-C:H coatings $[1,2,6,7,19-21]$ and which was already identified in a number of earlier studies also in W-C:H coatings [10, 18, 23, 24, 35].

In HiTUS WC coating without $\mathrm{C}_{2} \mathrm{H}_{2}$ additions, $\mathrm{CoF}$ around 0.5 was typical for the stable regime (Fig. 9). The addition of $2 \mathrm{sccm}$ acetylene reduced CoF values to 0.25 0.15 . However, despite this $\mathrm{CoF}$ reduction, further reduction of $\mathrm{CoF}$ at higher acetylene additions was not achieved due to relatively rapid wear and complete removal of the coatings prior to the achievement of a well-defined stable regime. Low wear resistance and short lifetime of the coatings in these cases may be attributed to their low hardness (Fig. 6). Low hardness implies low yield stress of the coating and because higher load $(10 \mathrm{~N})$ was used in these tests, the corresponding contact stresses may exceed yield stress of the substrate and of the coating. The plastic deformation of the substrate would facilitate coating fracture and change of the wear mechanism to abrasion by coating debris. Thus, tribolayer could not form, CoF could not be reduced and coating lifetime was therefore shortened. For a fair
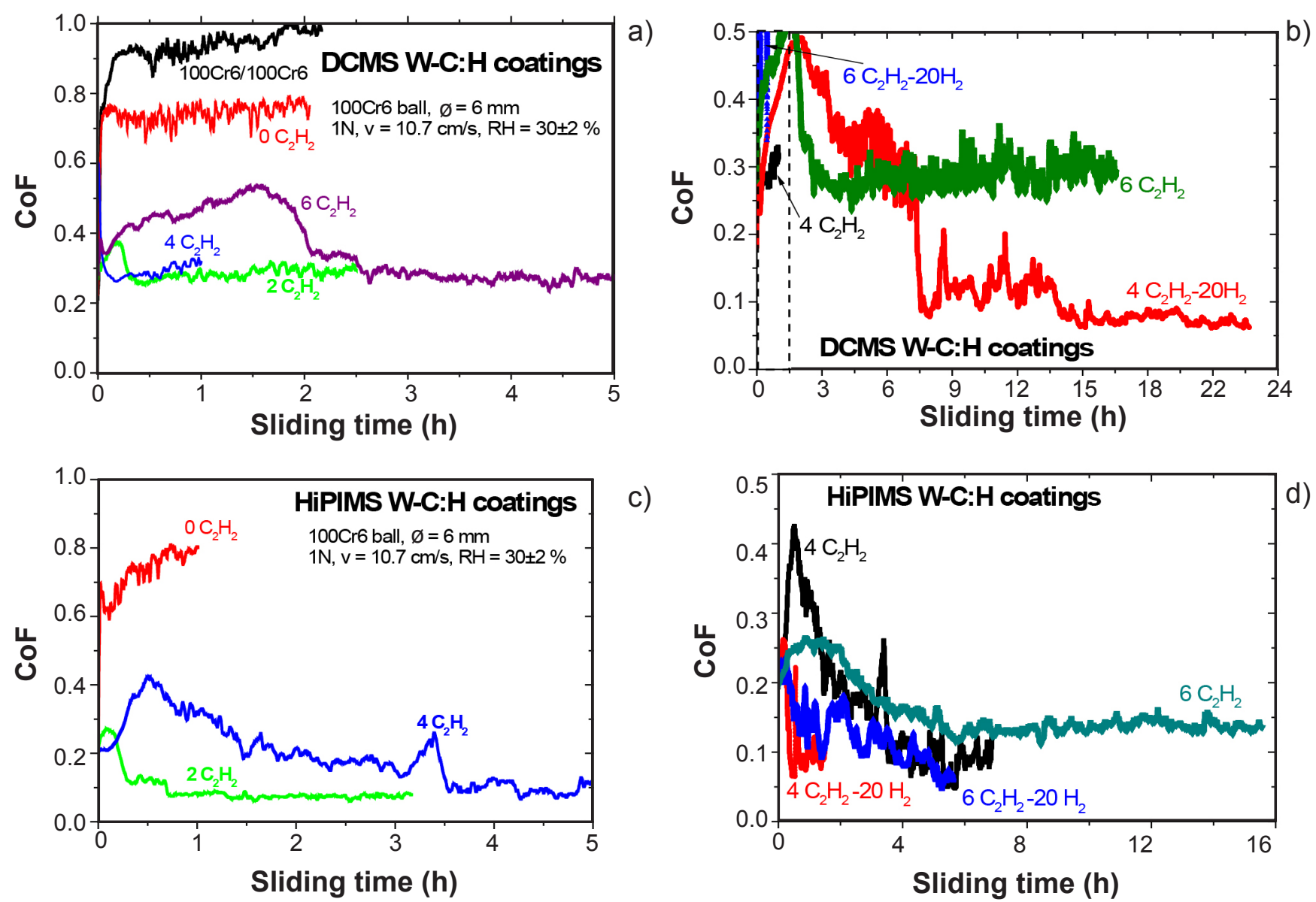

C)

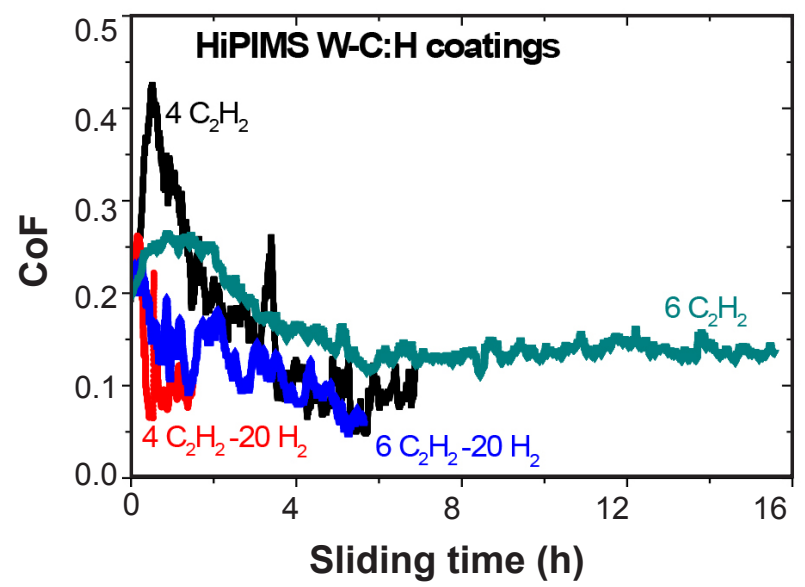

d)

Figure 7: Friction curves as function of acetylene flow and hydrogen flow in DCMS (a,b) and HiPIMS (c,d) W-C:H coatings, respectively. 


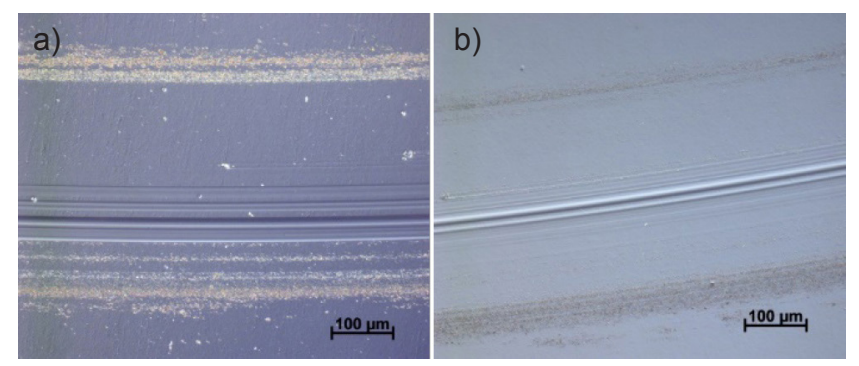

Figure 8: Wear tracks in HiPIMS W-C:H coatings after longterm friction tests: a) after almost $17 \mathrm{~h}$ of testing $(6.3 \mathrm{~km}$ sliding distance) in the coating deposited with $6 \mathrm{sccm} \mathrm{C}_{2} \mathrm{H}_{2}$ addition into $\mathrm{Ar}$ atmosphere; b) after $7.3 \mathrm{~h}$ (intentional interruption) long test $(2.3 \mathrm{~km})$ in the coating deposited with $6 \mathrm{sccm} \mathrm{C}_{2} \mathrm{H}_{2}+20 \mathrm{sccm} \mathrm{H}_{2}$ additions.

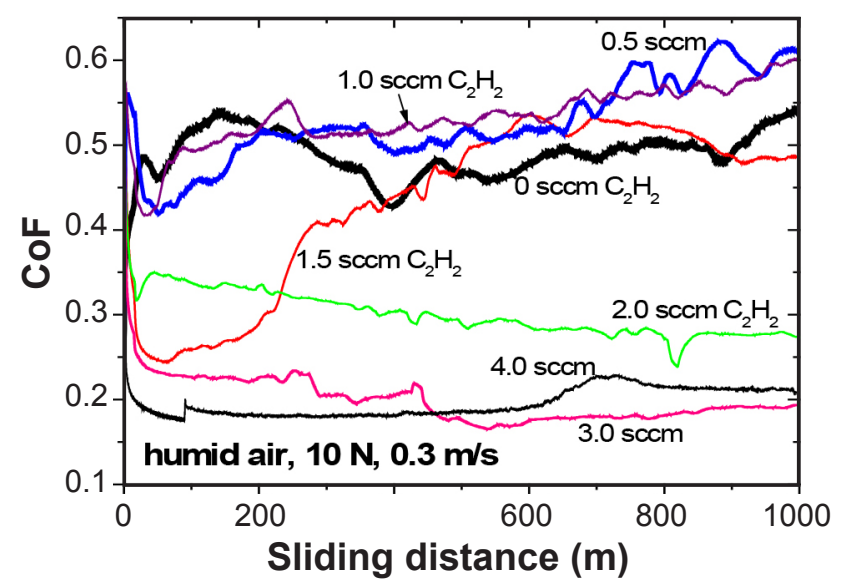

Figure 9: Friction curves in the HiTUS W-C:H coatings at different acetylene flows

comparison, additional tribological experiments at the same load as in DCMS and HiPIMS coatings will be performed.

The current measurements of $\mathrm{H}_{\mathrm{IT}}, \mathrm{E}_{\mathrm{IT}}$ and $\mathrm{CoF}$ indicated that they depend on various parameters involving deposition technique and composition of the reactive gases. The addition of acetylene into Ar atmosphere transformed into the addition of free (hydrogenated) carbon in the coating and in a gradual transition of the coating structure from nanocrystalline (textured or random in DCMS and HiPIMS, respectively) to nanocomposite and amorphous. Hydrogen additions into atmosphere exhibited sufficient influence only on deposition rates, its effects on structure and properties were considerably smaller. Such behavior can be explained within the existing a-C:H growth models assuming that acetylene fragments containing hydrogen may attach only to the sites activated by impinging hydrogen. Thus, when the effects of reactive gas type and hybridization are neglected, hydrogen affects mostly the growth rate and acetylene controls the level of hydrogenation. The effects of various techniques stem from the energy which drives the whole deposition process. Much higher peak power in HiPIMS would produce more homogeneous nanocomposite structure with low sensitivity of hardness and elastic modulus to the composition of the reactive atmosphere. Tribological behavior seems to be strongly influenced by the amount of free carbon and its hydrogenation. CoF usually follows the hardness in W-C coatings: higher hardness is accompanied by an increase of $\mathrm{CoF}$ and vice versa due to the presence of soft lubricous carbon phase [10]. At the same time and in accordance with the model of Donnet and Erdemir [1922], CoF of hydrogenated carbon-based coatings in humid or dry atmospheres may be affected by the formation of different types of tribolayer between two contacting bodies. Relatively low CoF after prolonged run-in periods combined with negligible wear achieved in the coatings deposited with sufficiently high acetylene (and hydrogen) additions (Fig. 7) indirectly suggested that similar tribolayers developed also in the current coatings. Another indirect evidence for more complex than the single conformable correlation between hardness and $\mathrm{CoF}$ is illustrated in Fig. 10. It shows $\mathrm{CoF}$ vs. $\mathrm{H}_{\mathrm{IT}}$ relationships in the studied HiTUS W-C:H coatings correlated with the composition reactive atmosphere in each data point (the first number corresponds to $\mathrm{C}_{2} \mathrm{H}_{2}$ and the second number to $\mathrm{H}_{2}$ flow). The WC (true phase composition is not considered and 'WC' is used only for a general description of coatings deposited without acetylene addition) coating obtained in standard PVD regime exhibited the highest hardness and $\mathrm{CoF}$ (shaded area on the righthand side). The addition of acetylene meant that PECVD was added to the existing PVD regime and the deposition process became hybrid. The increase of acetylene flow resulted not only in a congruent decrease of $\mathrm{CoF}$ and $\mathrm{H}_{\mathrm{IT}}$ well known from the literature [10] but also in the increase of PECVD contribution into the overall deposition process. The minimum properties were reached at around $8-12 \mathrm{sccm}$ acetylene addition. The additions of hydrogen at these acetylene additions produced very different behavior: $\mathrm{CoF}$ increased whereas hardness decreased with the increase of hydrogen flow. Apparently, PECVD part in the deposition process became dominant (shaded area on the left-hand side) and soft a-C:H coatings only slightly doped by WC were formed.

The same approach applied to $\mathrm{CoF}-\mathrm{H}_{\mathrm{IT}}$ relationships in

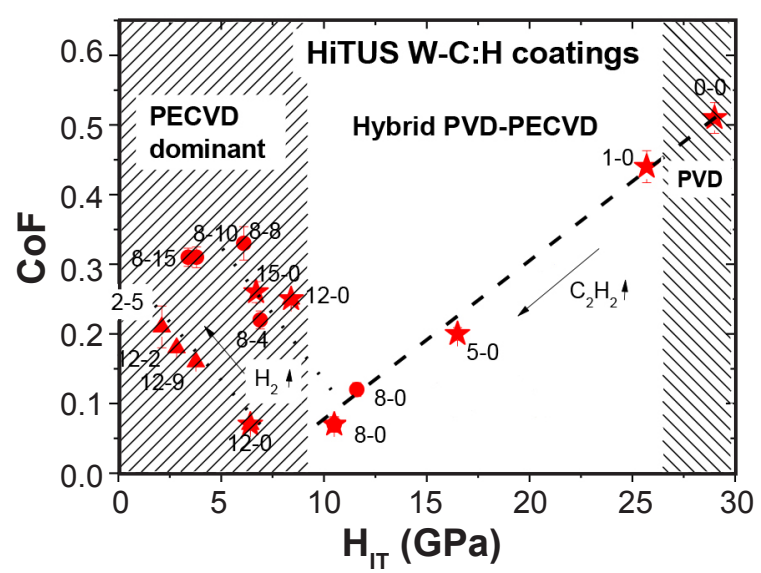

Figure 10: Correlations between $\mathrm{H}_{\mathrm{IT}}$ and $\mathrm{CoF}$ in HiTUS W-C:H coatings in dependence on the composition of reactive atmosphere during hybrid PVD-PECVD deposition. The first number corresponds to $\mathrm{C}_{2} \mathrm{H}_{2}$ and the second number to $\mathrm{H}_{2}$ flow added into Ar atmosphere. 
DCMS and HiPIMS W-C:H coatings in Fig. 11 points to similarities and differences among the studied deposition techniques. PVD process produced WC coatings with hardness strongly affected by the corresponding technique: DCMS coatings were harder than those made by HiPIMS and HiTUS, most probably due to textured growth. Hybrid PVD-PECVD and PECVD dominant processes exhibited very similar behavior in DCMS and HiTUS W-C:H coatings. However, HiPIMS W-C:H coatings did not follow these trends and their $\mathrm{CoF}$ and $\mathrm{H}_{\mathrm{IT}}$ values clustered in a small region around $\mathrm{H}_{\mathrm{IT}}=20 \mathrm{GPa}$ and $\mathrm{CoF}=0.1$. The effects of acetylene and hydrogen additions were minimized compared to those in DCMS and HiTUS coatings. The most natural reason for such behavior in HiPIMS has to be related to extremely high peak power density resulting in more efficient acetylene fragmentation. However, for direct correlations of the addition of reactive gases and resulting properties in the studied techniques, additional ERDA/RBS and XPS studies are required to determine the amount of free carbon as well as the level of its hydrogenation and hybridization.

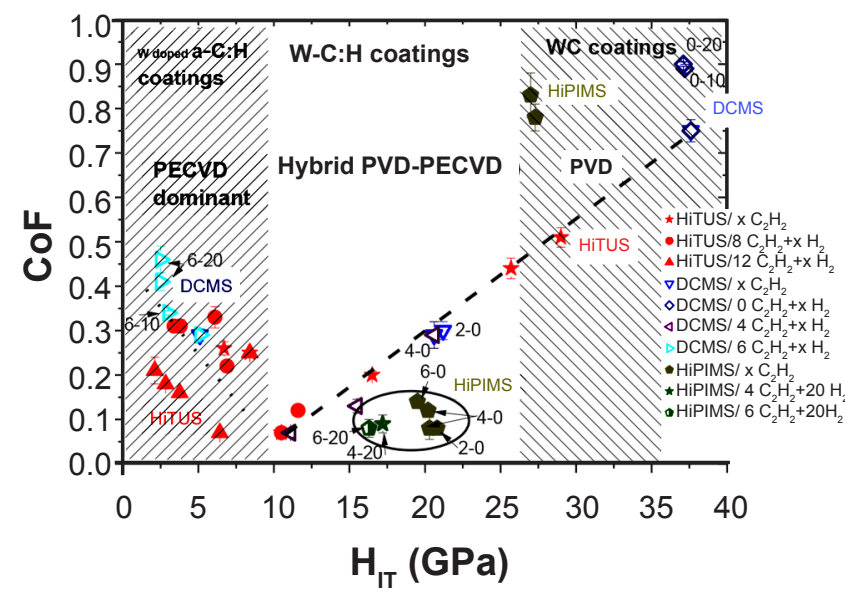

Figure 11: Comparison of the $\mathrm{CoF}-\mathrm{H}_{\mathrm{IT}}$ relationships between the W-C:H coatings deposited by DCMS, HiPIMS and HiTUS techniques. The marks at individual data points correspond to the additions of $\mathrm{C}_{2} \mathrm{H}_{2}$ and $\mathrm{H}_{2}$ in $\mathrm{Ar}$ atmosphere during deposition.

\section{CONCLUSIONS}

Current investigations of the structure, hardness and friction behavior in DCMS, HiPIMS and HiTUS W-C:H coatings in dependence on the additions of acetylene and hydrogen revealed: i) a transition from true PVD process without these additions toward hybrid PVD-PECVD processes and even PECVD dominant processes with the increasing additions of acetylene and hydrogen; ii) this transition is accompanied by the coating structure evolution from nanocrystalline toward nanocomposite and amorphous structure regardless of the deposition techniques used in the study; however, the differences among them seem to result only from different levels of reactive gas additions when transition from one structure to another occurs; iii) despite differences in absolute values, deposition rates in all deposition techniques increased linearly with the increase of acetylene flow; at a certain limit flow which seems to be specific for each energy and technique, the deposition rates saturated; such dependencies were rationalized assuming limited energy available for acetylene fragmentation; iv) the addition of acetylene was found to be more effective than the addition of hydrogen in terms of the modification of mechanical and tribological properties; v) the relationships between hardness and coefficient of friction in DCMS and HiTUS W-C:H coatings deposited in hybrid PVD-PECVD regime (i.e. under relatively low acetylene flows and moderate portion of PECVD) follow standard congruent tendencies whereas PECVD dominated deposition process produces coatings with different dependencies; in contrary, HiPIMS W-C:H coatings show low sensitivity to the influence of acetylene and hydrogen additions; and vi) HiPIMS is able to produce W-C:H coatings with low coefficients of friction and moderate hardness over wide range of acetylene additions; this seems to be a principal advantage of HiPIMS techniques in this class of coatings compared to HiTUS and DCMS.

\section{ACKNOWLEDGMENTS}

The motivation and the support provided by the project M-ERA RUS Plus "LightMat4Space" as well as financial support by the projects APVV-17-0320, APVV-15-0168, and APVV 14-0173 are acknowledged. The equipment used in the work was acquired from the project "Research Centre of Advanced Materials and Technologies for Recent and Future Applications" PROMATECH, ITMS: 26220220186. The contribution of P. Zubko (at IMR SAS, currently at USS, Košice, Slovakia) to the preparation of HiTUS W-C:H coatings is acknowledged.

\section{REFERENCES}

[1] C. Donnet, A. Erdemir, in "Tribology of diamond-like carbon films: fundamentals and applications", C. Donnet, A. Erdemir (Eds.), Springer, New York (2008) 1.

[2] Y. Pauleau, in "Tribology of diamond-like carbon films: fundamentals and applications", C. Donnet, A. Erdemir (Eds.), Springer, New York (2008) 102.

[3] J.C. Sánchez-López, A. Fernández, in "Handbook of modern tribology”, B. Bhushan (Ed.), CRC Press, Boca Raton (2008) 311 .

[4] S. Veprek, R.F. Zhang, M.G.J. Veprek-Heijman, S.H. Sheng, A.S. Argon, Surf. Coat. Technol. 204 (2010) 1898.

[5] M.D. Abad, M.A. Muñoz-Márquez, S. El Mrabet, A. Justo, J.C. Sánchez-López, Surf. Coat. Technol. 204 (2010) 3490.

[6] A. Erdemir, O.L. Eryilmaz, I.B. Nilufer, G.R. Fenske, Diamond Relat. Mater. 9 (2000) 632.

[7] A. Erdemir, I.B. Nilufer, O.L. Eryilmaz, M. Beschliesser, G.R. Fenske, Surf. Coat. Technol. 120-121 (1999) 589.

[8] F. Lofaj, M. Ferdinandy, G. Cempura, J. Dusza, J. Eur. Ceram. Soc. 32 (2012) 2043. 
[9] W. Wang, V.O. Pelenovich, M.I. Yousaf, S. Yan, H. Bin, Z. Wang, A.B. Tolstogouzov, P. Kumar, B. Yang, D.J. Fu, Vacuum 132 (2016) 31.

[10] S. El Mrabet, M.D. Abad, J.C. Sánchez-López, Surf. Coat. Technol. 206 (2011) 1913.

[11] F. Lofaj, L. Kvetková, P. Hviščová, M. Gregor, M. Ferdinandy, J. Eur. Ceram. Soc. 36 (2016) 3029.

[12] F. Lofaj, P. Hviščová, P. Zubko, D. Németh, M. Kabátová, Int. J. Refract. Met. H., doi:10.1016/ijrmhm.2016.12.015 (2016).

[13] T. Schmidtová, P. Souček, V. Kudrle, P. Vašina, Surf. Coat. Technol. 232 (2013) 283.

[14] N.J.M. Carvalho, J.Th.M. De Hosson, Thin Solid Films 388 (2001) 150.

[15] A. von Keudell, Thin Solid Films 402 (2002) 1.

[16] A. von Keudell, M. Meier, C. Hopf, Diamond Relat. Mater. 11 (2002) 969.

[17] C. Ruset, E. Grigore, C. Luculescu, X. Li, H. Dong, Thin Solid Films 519 (2011) 4045.

[18] M. Makowka, W. Pawlak, P. Konarski, B. Wendler, Diamond Relat. Mater. 67 (2016) 16.

[19] C. Donnet, A. Grill, Surf. Coat. Technol. 94-95 (1997) 456.

[20] A. Erdemir, Tribol. Int. 37 (2004) 1005.

[21] A. Erdemir, Surf. Coat. Technol. 146-147 (2001) 291.

[22] A. Erdemir, J. Fontaine, C. Donnet, in "Tribology of diamond-like carbon films: fundamentals and applications", C. Donnet, A. Erdemir (Eds.), Springer, New York (2008) 237. [23] A.A. Voevodin, J.P. O’Neill, J.S. Zabinski, Thin Solid Films 342 (1999) 194.

[24] F.Lofaj, M.Kabátová, M.Klich,D. Vaňa, J.Dobrovodský, Ceram. Int., in press.

[25] J. Robertson, Diamond Relat. Mater. 3 (1994) 361.

[26] W. Jacob, Thin Solid Films 326 (1998) 1.

[27] T. Schwarz-Selinger, A. von Keudell, W. Jacob, J. Appl. Phys. 81 (1997) 1531.

[28] D. Thiry, A. De Vreese, F. Renaux, J.L. Colaux, S. Lucas, Y. Guinet, L. Paccou, E. Bousser, R. Snyders, Plasma Process. Polym. 13 (2016) 316.

[29] A. von Keudell, W. Jacob, J. Appl. Phys. 6 (1999) 3988.

[30] P.N. Maya, U. von Toussaint, W. Jacob, Diamond Relat. Mater. 40 (2013) 41.

[31] V. Kouznetesov, K. Macák, J.M. Schneider, U. Helmersson, I. Petrov, Surf. Coat. Technol. 122 (1999) 290.

[32] W. Moller, J. Nucl. Mater. 162 (1989) 138.

[33] T. Csanádi, M. Bl'anda, N.Q. Chinh, P. Hvizdoš, J. Dusza, Acta Mater. 83 (2015) 397.

[34] R. Žemlička, P. Souček, P. Vogl, M. Jílek, V. Buršíková, P. Vašina, Y.T. Pei, Surf. Coat. Technol. 315 (2017) 17.

[35] Y. Liu, M. Gubisch, T. Haensel, L. Spiess, J.A. Schaefer, Tribol. Int. 39 (2006) 1584.

(Rec. 13/09/2018, Rev. 16/11/2018, Ac. 21/11/2018) 